\title{
Treatment of non-oliguric hyperkalaemia with inhaled salbutamol in premature infants with severe respiratory distress syndrome
}

\author{
EDA VIDMAR ${ }^{2}$, MAJA PAVCNIK ${ }^{1,2}$ \\ ${ }^{1}$ Department of Paediatric Surgery and Intensive Care, University Medical Centre Ljubljana, Slovenia \\ ${ }^{2}$ Faculty of Medicine - Division of Paediatrics, University of Ljubljana, Slovenia
}

Corresponding author:

Maja Pavcnik

Department of Paediatric Surgery and Intensive Care

University Medical Centre Ljubljana

Bohoriceva 20, 1525 Ljubljana, Slovenia

Phone: +386-1-522-48-29

Fax: +386-1-522-11-09

E-mail:maja.pavcnik@kclj.si

\section{ABSTRACT}

Non-oliguric hyperkalaemia (NOHK) in neonates is defined as a plasma potassium level $>6.5 \mathrm{mmol} / \mathrm{L}$ in the presence of urine output $\geq 1 \mathrm{~mL} / \mathrm{kg} / \mathrm{h}$ during the first 72 hours of life. It is characterized by a rapid rise of serum potassium to excessively high values, a high risk of cardiac arrhythmias and no occurrence after 72 hours of birth. NOHK commonly occurs in premature neonates, especially in those with a gestational age $<28$ weeks, with only a few reports of this entity in moderate or late preterm neonates. The effectiveness and safety of different treatments for NOHK is uncertain and currently there is no firm treatment recommendation. We describe the case of a moderately premature neonate $(32+2$ weeks gestation), with severe neonatal respiratory distress syndrome, who developed NOHK that was treated with inhaled salbutamol. When salbutamol is used for the treatment of $\mathrm{NOHK}$, an initial paradoxical rise in potassium levels should always be taken into account to avoid cardiac arrhythmias.

Key words: non-oliguric hyperkalaemia, premature, infants, salbutamol, hyperkalaemia

\section{INTRODUCTION}

Non-oliguric hyperkalaemia (NOHK) is a common and serious complication in premature neonates, especially in those with very low birth weight $(<1500 \mathrm{~g})$ and/or very preterm ( $\leq 28$ weeks gestational age). $(1,2)$ The reported incidence of NOHK is $11 \%$ to $52 \%$. (3-5) With increased survival of premature neonates, NOHK is becoming more common. (5)

Reversible hyperkalaemia in premature neonates was first reported in 1959 by Usher. (6) Characteristics of NOHK as we know it today were described by Perkkiö and Räihä (7) in 1977. NOHK is defined as a serum potassium $\geq 6.5 \mathrm{mmol} / \mathrm{L}$ during the first 72 hours of life in a non-haemolysed arterial or venous blood sample in the presence of urine output $\geq 1 \mathrm{~mL} / \mathrm{kg} / \mathrm{h}$. (2) It is characterized by a rapid rise in serum potassium to excessively high values after birth in premature neonates, a high risk of cardiac arrhythmias and no occurrence after 72 hours of birth. The pathophysiology of NOHK is not completely understood. Current evidence suggests that it is mainly due to a shift in potassium from the intra- into the extracellular spaces because of immature function of the $\mathrm{Na}+/ \mathrm{K}+$ ATPase in premature neonates. $(5,8-10)$ More than $80 \%$ of neonates with NOHK are extremely low birth weight (ELBW) infants with gestational age below 28 weeks. (4) Few cases have been reported in moderate to late preterm neonates. $(1,4)$ The effectiveness and safety of different treatment options for NOHK is uncertain and currently there is no firm treatment recommendation. (2) We describe a case of a moderately premature neonate $(32+2$ weeks gestation) with severe neonatal respiratory distress syndrome, who developed NOHK that was treated with inhaled salbutamol.

\section{CASE REPORT}

A premature girl was admitted to the interdisciplinary neonatal and paediatric intensive care unit (ICU) of the Department

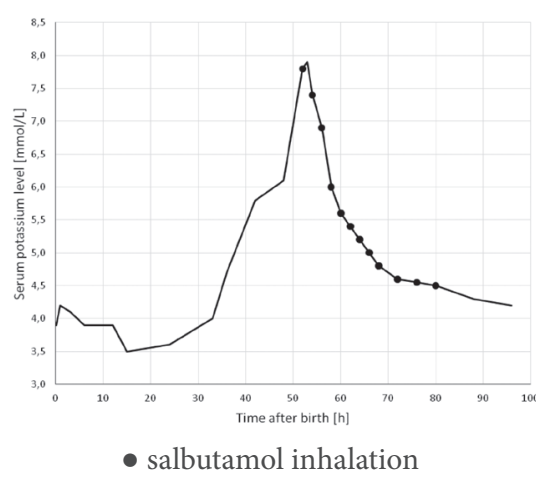

Figure 1. Serum potassium levels in patient with NOHK. Inhalations of salbutamol are marked

of Paediatric Surgery and Intensive Care, University Medical Centre Ljubljana, Slovenia because of respiratory distress. Due to incipient premature labour, the mother received a course of antenatal steroids (betamethasone) 16 days before delivery. The girl was delivered at 32 weeks and 2 days gestational age at the regional maternity hospital by caesarean section after minor antepartum haemorrhage because of placenta praevia and persistent foetal tachycardia. The girl weighed $1900 \mathrm{~g}$ and appeared vigorous, with spontaneous respirations; the 1-minute and 5-minute Apgar scores were 8 and 9, respectively. Haemoglobin level at birth was $126 \mathrm{~g} / \mathrm{L}$, which was an indicator that she suffered some blood loss because of placenta praevia. Shortly after birth she developed tachypnoea with shallow respirations and retractions. Features of severe hyaline membrane disease were found on chest X-ray. Endotracheal intubation was performed and assisted 
Table 1. Blood gas, electrolytes, urea, creatinine and glucose levels at different times after birth. Samples at postnatal age of 4 minutes and $1 \mathrm{~h}$ are umbilical venous blood, all other samples are arterial.

\begin{tabular}{|c|c|c|c|c|c|c|c|c|c|c|c|c|}
\hline Age & $\mathrm{pH}$ & $\begin{array}{l}\text { Pco2 } \\
(\mathrm{kPa})\end{array}$ & $\begin{array}{l}\mathrm{HCO3} \\
(\mathrm{mmol} / \mathrm{L})\end{array}$ & $\begin{array}{l}\mathbf{K}+ \\
(\mathrm{mmol} / \mathrm{L})\end{array}$ & $\begin{array}{l}\mathrm{Na}+ \\
(\mathrm{mmol} / \mathrm{L})\end{array}$ & $\begin{array}{l}\mathrm{Ca}++ \\
(\mathrm{mmol} / \mathrm{L})\end{array}$ & $\begin{array}{l}\text { iCa } \\
(\mathrm{mmol} / \mathrm{L})\end{array}$ & $\begin{array}{l}\mathbf{P} \\
(\mathrm{mmol} / \mathrm{L})\end{array}$ & $\begin{array}{l}\mathrm{Mg}++ \\
(\mathrm{mmol} / \mathrm{L})\end{array}$ & $\begin{array}{l}\text { Urea } \\
(\mathrm{mmol} / \mathrm{L})\end{array}$ & $\begin{array}{l}\text { Creat } \\
(\mathrm{mmol} / \mathrm{L})\end{array}$ & $\begin{array}{l}\text { Glu } \\
(\mathrm{mmol} / \mathrm{L})\end{array}$ \\
\hline $4 \mathrm{~min}$ & 7.26 & 7.3 & 21.6 & 3.9 & 135 & & 1.49 & & & & & 4.6 \\
\hline $1 \mathrm{~h}$ & 7.08 & 9.8 & 15.0 & 4.2 & 137 & 1.83 & & & & & & 4.1 \\
\hline $3 \mathrm{~h}$ & 7.40 & 5.5 & 19.8 & 4.1 & 136 & & 1.2 & & & & & 7.2 \\
\hline $6 \mathrm{~h}$ & 7.05 & 5.9 & 11.3 & 3.9 & 141 & 1.76 & 1.07 & 2.53 & 0.82 & 4.8 & 74 & 16.7 \\
\hline $9 \mathrm{~h}$ & 7.17 & 5.9 & 15.8 & 3.9 & 133 & 1.98 & 1.03 & 3.0 & 0.86 & 4.3 & 84 & 24.1 \\
\hline $12 \mathrm{~h}$ & 7.31 & 4.5 & 16.3 & 3.9 & 134 & & 0.7 & & & & & 23.8 \\
\hline $15 \mathrm{~h}$ & 7.17 & 5.9 & 15.6 & 3.5 & 143 & 1.48 & 0.8 & 2.93 & 0.51 & 4.3 & 66 & 11.3 \\
\hline $24 \mathrm{~h}$ & 7.38 & 5.2 & 20.7 & 3.6 & 140 & 1.72 & 1.08 & 2.85 & 1.1 & 6.1 & 72 & 8.9 \\
\hline $33 \mathrm{~h}$ & 7.29 & 7.2 & 25.1 & 4.0 & 138 & 2.0 & 1.12 & 2.63 & 1.1 & 6.1 & 44 & 9.0 \\
\hline $36 \mathrm{~h}$ & 7.31 & 5.6 & 20.5 & 4.7 & 136 & 2.23 & 1.02 & 2.77 & 1.0 & 7.3 & 79 & 5.4 \\
\hline $42 \mathrm{~h}$ & 7.32 & 5.5 & 20.9 & 5.8 & 138 & 2.18 & 0.95 & 2.77 & 1.0 & 7.3 & 78 & 5.9 \\
\hline $48 \mathrm{~h}$ & 7.31 & 6.0 & 22.0 & 6.1 & 142 & 1.82 & 1.1 & 2.79 & 0.9 & 7.9 & 88 & 9.0 \\
\hline $52 \mathrm{~h}$ & 7.34 & 5.4 & 21.0 & 7.8 & 140 & 2.0 & 1.1 & 2.95 & 1.0 & 7.8 & 90 & 10.0 \\
\hline $53 \mathrm{~h}$ & 7.33 & 5.5 & 20.0 & 7.9 & 139 & 2.1 & 1.4 & 2.85 & 1.1 & 7.5 & 89 & 9.5 \\
\hline $54 \mathrm{~h}$ & 7.33 & 5.6 & 20.0 & 7.4 & 138 & & 1.2 & & & & & 10.5 \\
\hline $56 \mathrm{~h}$ & 7.34 & 5.7 & 21.0 & 6.9 & 138 & & 1.3 & & & & & 9.0 \\
\hline $58 \mathrm{~h}$ & 7.36 & 5.2 & 20.0 & 6.0 & 139 & & 1.1 & & & & & 9.5 \\
\hline $60 \mathrm{~h}$ & 7.39 & 4.9 & 20.1 & 5.6 & 140 & 2.1 & 1.2 & 2.80 & 1.0 & 8.8 & 75 & 6.8 \\
\hline $64 \mathrm{~h}$ & 7.41 & 5.6 & 20.0 & 5.2 & 143 & 1.8 & 1.0 & 2.72 & 0.8 & 8.7 & 75 & 4.2 \\
\hline $68 \mathrm{~h}$ & 7.40 & 5.9 & 22.0 & 4.8 & 143 & 2.1 & 1.1 & 2.74 & 0.9 & 8.3 & 72 & 5.6 \\
\hline $72 \mathrm{~h}$ & 7.39 & 5.8 & 24.0 & 4.6 & 144 & 2.1 & 1.1 & 2.81 & 0.8 & 8.2 & 75 & 8.0 \\
\hline $80 \mathrm{~h}$ & 7.42 & 6.0 & 24.0 & 4.5 & 143 & 2.4 & 1.2 & 3.24 & 0.9 & 8.0 & 70 & 9.7 \\
\hline $88 \mathrm{~h}$ & 7.38 & 6.1 & 22.0 & 4.3 & 140 & 2.5 & 1.3 & 2.7 & 0.8 & 8.0 & 65 & 8.5 \\
\hline $96 \mathrm{~h}$ & 7.37 & 6.0 & 23.0 & 4.2 & 142 & 2.2 & 1.2 & 2.0 & 0.8 & 7.5 & 60 & 5.3 \\
\hline
\end{tabular}

$\mathrm{Ca}++$, calcium ion; creat., creatinine; glu., glucose; $\mathrm{HCO} 3$, hydrogen carbonate; iCa, ionized calcium; $\mathrm{K}+$, potassium ion; $\mathrm{Mg}++$, magnesium ion; P, phosphate; PCO2, partial pressure of carbon dioxide.

ventilation begun. The baby developed bilateral pneumothoraxes, requiring chest drainage. Transfer to a tertiary hospital was arranged. Surfactant, high-frequency oscillator ventilation, and nitric oxide were administered. Due to anaemia she received a blood transfusion at postnatal age of 12 hours. Her respiratory status gradually improved ( 15 days of invasive and 20 days of non-invasive ventilation). Ultrasonography of the brain revealed grade 1 haemorrhage into the germinal matrix bilaterally. Because of bronchopulmonary dysplasia she needed supplemental oxygen until postnatal age of 6 months. Her neurodevelopmental status at postnatal age of 12 months was normal. Her renal function was normal.

Laboratory parameters were regularly checked after birth (table 1). Potassium serum concentrations $(\mathrm{K}+)$ were in the low normal range for the first 36 hours of life, despite rather low $\mathrm{pH}$ values (table 1, figure
1). Urinary output was monitored closely and was high - early polyuria (first day: 3.5 $\mathrm{ml} / \mathrm{kg} / \mathrm{h}$, second day $6.3 \mathrm{ml} / \mathrm{kg} / \mathrm{h}$, third day $5.6 \mathrm{ml} / \mathrm{kg} / \mathrm{h}$, fourth day $7.8 \mathrm{ml} / \mathrm{kg} / \mathrm{h}$, fifth day $7 \mathrm{ml} / \mathrm{kg} / \mathrm{h}$ ). There was hyperphosphataemia, hypocalcaemia and hypomagnesaemia. Due to early hyperglycaemia she received an insulin infusion for $7 \mathrm{~h}$ during the first day of life. After discontinuation of the insulin infusion, glucose levels were below $10 \mathrm{mmol} / \mathrm{L}$. At 42 hours of age $\mathrm{K}+$ rose to $5.8 \mathrm{mmoL} / \mathrm{L}$. She was receiving only potassium-free infusions. As seen in figure 1, a further increase in $\mathrm{K}+$ occurred with the maximum level reached at 53 hours of age (7.9 mmol/L). When the $\mathrm{K}+$ level reached $7.8 \mathrm{mmol} / \mathrm{L}$, tall peaked $\mathrm{T}$ waves were noticed on the ECG. The baby was already receiving supplementation with calcium gluconate every 6 hours due to low levels of ionized calcium. Despite this, an additional dose of calcium gluconate $10 \% 100$ $\mathrm{mg}(1 \mathrm{ml}) / \mathrm{kg}$ was administered and shortly thereafter the ECG normalized. When the $\mathrm{K}+$ level reached $7.8 \mathrm{mmol} / \mathrm{L}$, salbutamol was given by nebulizer $(400 \mu \mathrm{g}=200 \mu \mathrm{g} /$ $\mathrm{kg})$. The dose was repeated every 2 hours until the $\mathrm{K}+$ level fell below $5 \mathrm{mmol} / \mathrm{L}$, thereafter the dose was repeated every 4 hours for another 12 hours. The potassium level slightly increased after the first inhalation of salbutamol (figure 1), but declined rapidly thereafter and reached $6.0 \mathrm{mmol} / \mathrm{L}$ within 6 hours following the first inhalation. Changes in heart rate and blood pressure after salbutamol inhalation are shown in table 2.

\section{DISCUSSION}

Even though NOHK is most common in ELBW infants with a gestational age $<28$ weeks (4) and there are only a few reports of this entity in late preterm infants, $(1,4)$ our report emphasizes that NOHK can oc- 
Table 2. Difference in blood pressure and heart rate before and after salbutamol inhalation

\begin{tabular}{|c|c|c|c|c|c|c|}
\hline & \multicolumn{2}{|c|}{ Blood pressure (mmHg) } & \multicolumn{2}{|l|}{ MAP (mmHg) } & \multicolumn{2}{|c|}{ Heart rate (beats/min) } \\
\hline & Before inhalation & After inhalation & Before inhalation & After inhalation & Before inhalation & After inhalation \\
\hline 1 & $50 / 35$ & $69 / 53$ & 40 & 58 & 151 & 172 \\
\hline 2 & $62 / 41$ & $72 / 47$ & 48 & 55 & 146 & 148 \\
\hline 3 & $67 / 46$ & $68 / 47$ & 53 & 54 & 135 & 139 \\
\hline 4 & $60 / 44$ & $71 / 51$ & 49 & 58 & 137 & 142 \\
\hline 5 & $64 / 48$ & $66 / 50$ & 53 & 55 & 131 & 142 \\
\hline 6 & $64 / 43$ & $68 / 45$ & 50 & 53 & 135 & 144 \\
\hline 7 & $60 / 45$ & $62 / 44$ & 50 & 50 & 146 & 154 \\
\hline 8 & $66 / 44$ & $70 / 50$ & 51 & 57 & 148 & 160 \\
\hline 9 & $56 / 30$ & $72 / 54$ & 39 & 60 & 136 & 155 \\
\hline 10 & $67 / 45$ & $69 / 42$ & 52 & 51 & 134 & 139 \\
\hline 11 & $62 / 41$ & $65 / 43$ & 48 & 50 & 142 & 146 \\
\hline Median & & & 50 & 55 & 137 & 146 \\
\hline Q1 & & & 48 & 51 & 135 & 142 \\
\hline Q3 & & & 52 & 58 & 146 & 155 \\
\hline IQR & & & 4 & 7 & 11 & 13 \\
\hline $\mathrm{p}$-value & & & 0,0653 & & 0,0028 & \\
\hline
\end{tabular}

IQR, interquartile range; MAP, mean arterial blood pressure; Q1, first quartile; Q3, third quartile.

cur in more mature preterm infants. The characteristic feature of NOHK is a rapid rise in serum $\mathrm{K}+$ to high values during the first $72 \mathrm{~h}$ of life. (5) In our infant, as seen in Figure 1, K+ increased steeply between 42 and 52 hours of age. Low to normal $\mathrm{K}+$ levels during the first $36 \mathrm{~h}$ of life in our report underscores the importance of regular electrolyte checks in preterm infants during the first days of life.

Antenatal steroid therapy may reduce hyperkalaemia. $(8,11)$ In our report NOHK developed despite antenatal steroids. However, the peak $\mathrm{K}+$ level might have been higher in the absence of antenatal steroids. (8) Current evidence suggests NOHK is mainly due to a shift of $\mathrm{K}+$ from the intra- into the extracellular space because of immature function of the $\mathrm{Na}+/ \mathrm{K}+$ ATPase in premature neonates. (5,8-10) Antenatal steroids upregulate $\mathrm{Na}+\mathrm{K}+$ ATPase activity. (5,8-10) Impairment of the $\mathrm{Na}+$ / $\mathrm{K}+$ ATPase during hypoxia, acidosis and hypoglycaemia explain the association of NOHK with foetal distress, early metabolic acidosis, and early hyperglycaemia. $(3,4,12)$ All of these features were present in our patient.

Apart from the loss of $\mathrm{K}+$ into the extracellular space, other plausible mechanisms for hyperkalaemia are increased $\mathrm{K}+$ intake and decreased $\mathrm{K}+$ excretion, but these are not causes of NOHK (2) and were ruled out in the case described. Our patient was infused potassium-free solutions. The theoretical possibility of increased potassium load by red cell transfusion is very unlikely as transfusion was administered at $12 \mathrm{~h}$ of life and transfusion as a cause of NOHK has been ruled out by several authors. $(10,13-15)$ NOHK is not associated with decreased diuresis, reflecting diminished glomerular filtration and polyuria, as was seen in our case. $(3,13,16)$ NOHK has been shown to be unrelated to leakage of $\mathrm{K}+$ from cell disruption associated with bruising, intracranial haemorrhage, or haemolysis. $(5,13,17)$

NOHK is associated with a high risk of cardiac arrhythmias, $(5,8)$ especially with $\mathrm{K}+$ levels higher than $7 \mathrm{mmol} / \mathrm{l}$. $(5,6)$ Tall peaked $\mathrm{T}$ waves developed in our patient when the $\mathrm{K}+$ level reached $7.8 \mathrm{mmol} / \mathrm{L}$; the ECG quickly normalized after calcium administration. As mortality related to NOHK is reported to be $12 \%$ and in the report by Sychlowy et al. only one in seven infants with cardiac arrhythmias secondary to NOHK survived, (18) NOHK represents an emergency situation requiring prompt therapy. The high incidence of cardiac arrhythmias is probably related to the common occurrence of hypocalcaemia in preterm infants, with lowest values of $\mathrm{Ca}++$ occurring at a time when NOHK sets in. $(14,19)$

Several treatment approaches are used in $\mathrm{NOHK}$, all adapted from the treatment of hyperkalaemia due to renal failure in infants. However, hyperkalaemia in NOHK has a different pathogenesis. In view of the limited information from small studies, the effectiveness and safety of different treatment options for NOHK is uncertain and currently no treatment guidelines can be recommended. (2) Administra- tion of intravenous calcium is supported when ECG changes occur to counteract the arrhythmogenicity of hyperkalaemia. $(5,14,19)$

The effect of salbutamol on transmembrane $\mathrm{K}+$ flux has been studied in neonatal red blood cells under hyperkalaemic conditions and resulted in a $50 \%$ increase in net transmembrane $\mathrm{K}+$ flux. No such increase occurred in adult red blood cells. (20) Salbutamol inhalation or infusion is effective in lowering serum potassium concentrations in adults and children beyond the neonatal period. (5) Salbutamol treatment has only anecdotally been reported for the treatment of hyperkalaemia in neonates, usually as an infusion. (21) Singh et al. reported on the efficacy and safety of inhaled albuterol for the treatment of NOHK in premature neonates. (22) Our report is one of only a few that describes salbutamol inhalation for the treatment of NOHK and underscores the effectiveness of this treatment approach. In our case, salbutamol was given by nebulization every 2 hours until the $\mathrm{K}+$ level fell below $5 \mathrm{mmol} / \mathrm{L}$, thereafter the dose was repeated every 4 hours for another 12 hours. The $\mathrm{K}+$ decreased from a peak level to $6 \mathrm{mmol} / \mathrm{l}$ over the course of $6 \mathrm{~h}$. There are some safety concerns about salbutamol use in hyperkalaemia. (5) Firstly, salbutamol increases heart rate and blood pressure by stimulating $\beta 1$ adrenoceptors. In our case (table 2 ), the mean arterial pressure and heart rate increased significantly after salbutamol inhalation, but this adrenergic stimulation was not excessive and 
clinically relevant. Secondly, a slight initial rise in $\mathrm{K}+(\approx 0.1 \mathrm{mmol} / \mathrm{L})$ has been reported between 1 and 3 minutes after salbutamol administration, before the hypokalaemic effect takes place. (23) We noticed the same slight transient increase in $\mathrm{K}+\quad(0.1$ $\mathrm{mmol} / \mathrm{L}$ ) after the first dose of salbutamol followed by a significant decrease in $\mathrm{K}+$. The early paradoxical increase in $\mathrm{K}+$ may be the result of $\mathrm{K}+$ release from skeletal muscle after $\beta 2$ adrenoceptor stimulation. Whether this increase in $\mathrm{K}+$ in already hyperkalaemic infants may provoke cardiac arrhythmias, especially as salbutamol also facilitates cardiac excitability through $\beta 1$ adrenoceptor stimulation, is unknown.

To conclude, this report underscores the need to recognize the possibility of NOHK in moderately and late preterm infants as well as in very preterm infants. Even in the face of low or normal $\mathrm{K}+$ during the first $24 \mathrm{~h}$ of life, $\mathrm{K}+$ should be checked every six hours during the first days of life as $\mathrm{K}+$ can quickly rise and lead to rhythm disturbances. As seen in our case, salbutamol inhalation can effectively and rapidly lower
$\mathrm{K}+$ in NOHK, but the paradoxical increase in $\mathrm{K}+$ during the first minutes following administration needs to be taken into account. It seems reasonable to administer calcium first to stabilize the myocardium and then commence salbutamol inhalation. With no absolute treatment recommendation, and in view of the limited information from small studies, the effectiveness of potentially beneficial interventions should be tested in further studies.

\section{REFERENCES}

1. Xiong X, Chen D, Zhang J, Mao J, Li J. Nonoliguric hyxperkalemia in a late preterm infant with severe birth asphyxia. Transl Pediatr 2013;2:48-52.

2. Vemgal P, Ohlsson A. Intervetions for non-oliguric hyperkalemia in preterm neonates. Cochrane Database Syst Rev 2012 (cited 2017 February 19); vol5. Available from: http://onlinelibrary.wiley.com/doi/10.1002/14651858.CD005257.pub3/

3. Brion LP, Schwartz GJ, Campbell D, Fleischman. Early hyperkalemia in very low birthweight infants in the absence of oliguria. Arch Dis Child 1989;64:720-2.

4. Yaseen H, Khalaf M, Dana A, Yaseen N, Darwich M. Salbutamol versus cation-exchange resin (kayexalate) for the treatment of nonoliguric hyperkalemia in preterm infants. Am J Perinatol 2008;25:193-7.

5. Mildenberger E, Versmold HT. Pathogenesis and therapy of non-oliguric hyperkalemia of the premature infant. Eur J Pediatr 2002;161:415-22.

6. Usher R. The respiratory distress syndrome of prematurity. I. Changes in potassium in the serum and the electrocardiogram and effects of therapy. Pediatr 1959;24:562-76.

7. Perkkiö M, Räihä N. Neonatal hyperkalemia. Lancet 1977;1:143.

8. Omar SA, De Cristofaro JD, Agarwal BI, LaGamma EF. Effect of prenatal steroids on potassium balance in extremely low birthweight neonates. Pediatr 2000;106:561-7.

9. Sato K, kondo T, Iwao H, Honda S, Ueda K. Internal potassium shift in premature infants: cause of nonoliguric hyperkalemia. J Pediatr 1995;126:109-13.

10. Stefano JL, Norman ME, Morales MC, Goplerud JM, Mishra OP, Delivoria -Papadopoulos M. Decreased erythrocyte Na+/K+ATPase activity associated with cellular potassium loss in exetremely low birth infants with nonoliguric hyperkalemia. J Pediatr 1993;122:276-84.

11. Uga N, Nemoto Y, Ishii T, Kawase Y, Arai H, Tada H. Antenatal steroid treatment prevents severe hyperkalemia in very low-birthweight infants. Pediatr Int 2003;45:656-60.

12. Lang K. K+ metabolism. In: Greger R, Windhorst U, editors. Comprehensive human physiology, vol 2. From cellular mechanisms to integration. Springer; 1996. p. 1586-1587.

13. Gruskay J, Costarino AT, Polin RA, Baumgart S. Nonoliguric hyperkalemia in the premature infant weighing less than 1000 grams. J Pediatr 1988;113:381-6.

14. Kilbride HW, Cater G, Warady BA. Early onset hyperkalemia in extremely low birth weight infants. J Perinatol 1988;8:211-4.

15. Lorenz JM, Kleinman LI, Markarian K. Potassium metabolism in extremely low birth weight infants in the first week of life. J Pediatr 1997;131:81-6.

16. Shaffer SG, Kilbride HW, Hayen LK, Meade VM, Warady BA. Hyperkalemia in very low birth weight infants. J Pediatr 1992;121:2759.

17. Fukuda Y, Kojima T, Ono A, Matsuzaki S, Iwase S, Kobayashi Y. Factors causing hyperkalemia in premature infants. Am J Pernatol 1989;6:76-9.

18. Sychlowy A, van der Gaag H, Hannen-Hofheinz I. Hyperkalemia - a life threatening early complication of asphyxia in premature infants. Monatsschr Kinderheilkd 1990;138:62-5.

19. Bennet LN, Myers TF, Lambert GH. Cecal perforation associated with sodium polystyrene sulfonate-sorbitol enemas in a 650 gram infant with hyperkalemia. Am J Perinatol 1996;13:167-70.

20. Angelopoulous M, Leitz H, Lambert G, MacGilvray S. In vitro analysis of the $\mathrm{Na}+\mathrm{K}+$ ATPase activity in neonatal and adult red blood cells. Biol Neonate 1996;69:140.

21. Mildenberger E, Versmold H. Results of a national survey in Germanyon incidence and therapy of the nonoliguric hyperkalemia of the premature infant. Z Geburtsh Neonatol 2002;206:9-14.

22. Singh BS, Sadiq HF, Noguchi A, Keenan WJ. Efficacy of albuterol inhalation in treatmentof hyperkalemia in premature neonates. J Pediatr 2002;141:16-20.

23. Mandelberg A, Krupnik Z, Houri S, Smetana S, Gilad E, Matas Z, Priel IE. Salbutamol metered-dose inhaler with spacer for hyperkalemia. Chest 1999;115:617-22. 